EGU2020-17837

https://doi.org/10.5194/egusphere-egu2020-17837

EGU General Assembly 2020

(c) Author(s) 2020. This work is distributed under

the Creative Commons Attribution 4.0 License.

\title{
Gross Primary Production and False Spring: a spatio-temporal analysis
}

Emma Izquierdo-Verdiguier ${ }^{1}$, Raúl Zurita-Milla ${ }^{2}$, Álvaro Moreno-Martinez ${ }^{3,4}$, Gustau Camps-Valls ${ }^{3}$, Anja Klisch ${ }^{1}$, Clement Atzberger, and Steven W. Running ${ }^{4}$

'Institute of Geomatics, University of Natural Resources and Life Sciences Vienna (BOKU), Vienna, Austria

(emma.izquierdo@boku.ac.at)

${ }^{2}$ Faculty of Geo-Information Science and Earth Observation (ITC), University of Twente, Enschede, the Netherlands

${ }^{3}$ Image Processing Laboratory(IPL) Universitat de València, Paterna, Spain

${ }^{4}$ Numerical Terradynamic Simulation Group, University of Montana, Missoula, USA

Phenological information can be obtained from different sources of data. For instance, from remote sensing data or products and from models driven by weather variables. The former typically allows analyzing land surface phenology whereas the latter provide plant phenological information. Analyzing relationships between both sources of data allows us to understand the impact of climate change on vegetation over space and time. For example, the onset of spring is advanced or delayed by changes in the climate. These alterations affect plant productivity and animal migrations.

Spring onset monitoring is supported by the Extended Spring Index (SI-x), which are a suite of regression-based models for key indicator plant species. These models (Schwartz et al. in 2013) are based on daily maximum and minimum temperature from the first day of the year (January $\left.1^{\text {st }}\right)$. The primary products of these models are the timing of first leaf and first bloom, but they also provide derivative products such as the timing of last freeze day and the risk of frost damage day (damage index) for each year. This information helps to understand if vegetation could have suffered from environmental stressors such as droughts or a late frost events. The effects of environmental stressors in vegetation could be captured by the false spring index, which relates the first leaf day and the last freeze day. Moreover, this information could be used to understand plant productivity as well as to evaluate the economic impact of climate change.

Previous works studied the relationship between remote sensing and plant level products by means of spatial-temporal analysis between Gross Primary Production (GPP) and a spring onset index. However, they did not consider the possible impact of false spring effect in these relationships. Here, we present a spatial-temporal analysis between GPP and the damage index to better understand the effect of false springs (in annual gross photosynthesis data). The analysis is done for the period 2000 to 2015 over the contiguous US and at spatial resolution of $1 \mathrm{~km}$. We used the MODIS annual sum of GPP and the damage and false spring indices derived from the SI-X models. 
